\title{
DA INTEGRAÇÃO DESEJADA ÀS PRÁTICAS PEDAGÓGICAS FRAGMENTADAS
}

\author{
A. L. F. QUEIROGA ${ }^{1 *}$ e R. F. SILVA ${ }^{2}$ \\ ${ }^{1}$ Instituto Federal de Educação, Ciência e Tecnologia da Paraíba- IFPB \\ ${ }^{2}$ Universidade Federal do Rio Grande do Norte - UFRN \\ anaqueiroga04@gmail.com*
}

Artigo submetido em outubro/2014 e aceito em dezembro/2014

DOI: $10.15628 /$ rbept.2014.3547

\begin{abstract}
RESUMO
Este estudo aborda caminhos da integração curricular nos Cursos Técnicos Integrados ao Ensino Médio, no Instituto Federal de Educação da Paraíba (IFPB), no período de 2004 a 2014. A questão de partida deste artigo é que: As práticas pedagógicas e integradoras (encontros, oficinas e reuniões pedagógicas) promovidas pela Instituição, nos cursos técnicos, convergem para integração curricular? Assumimos como pressuposto que essas práticas têm se mostrado fragmentadas em relação às estratégias de integração previstas nos Projetos Pedagógicos desses cursos. $O$ nosso objetivo é
\end{abstract}

compreender a relação entre essas práticas pedagógicas e integradoras promovidas pelo Instituto e as estratégias de integração contidas nos PPCs. Trata-se de um estudo comparativo das estratégias prenunciadas nos projetos e as práticas pedagógicas realizadas pelo Instituto, buscando a integração curricular. Como resultado, que se expõe de forma insistente, é que essas práticas caminham para a confirmação de que elas se apresentam fragmentadas e só dificultam a integração curricular anunciada.

PALAVRAS-CHAVE: Integração curricular, Projeto pedagógico e práticas pedagógicas.

\section{THE DESIRED INTEGRATION TO PRACTICES EDUCATIONAL FRAGMENTED}

\begin{abstract}
This study deals with ways for integrating the curriculum in the Technical Courses Integrated to High School Teaching, in the Federal Institute of Education, Science and Technology of Paraíba (IFPB), from 2004 to 2014. The starting question of this article is: do the pedagogical and integrative practices (meetings, workshops and pedagogical meetings) promoted by the IFPB, in the technical courses, converge on curriculum integration? We take for granted that these practices have shown to be fragmented with respect to integration strategies set out in the Pedagogical Projects of these courses. Our goal
\end{abstract}

is to understand the relationship between these pedagogical and integrative practices promoted by the IFPB and the integration strategies contained in the Pedagogical Projects of the Courses (PPC). It is a comparative study of the strategies mentioned in the projects and pedagogical practices carried out by the IFPB, seeking curricular integration. As a result, insistently exposed, is that these practices are moving towards confirmation that they are fragmented and they only hinder the announced curriculum integration.

KEYWORDS: Curricular integration, pedagogical Design and pedagogical practices. 


\section{INTRODUÇÃO}

Neste estudo, abordamos comparativamente as estratégias de Integração Curricular contidas nos Projetos dos Cursos Técnicos Integrados ao Ensino Médio, do Instituto Federal de Educação, Ciência e Tecnologia (IFPB), no período de 2004-2014, e as práticas pedagógicas e integradoras realizadas pelo IFPB - encontros, oficinas e reuniões pedagógicas. Trazemos, ainda, a discussão da competência como pedagogia orientadora da organização curricular, na década de 1990, diante da forte presença desse conceito no âmbito da educação profissional.

A questão de partida que mobilizou todo o estudo é que: As práticas pedagógicas e integradoras (encontros, oficinas e reuniões pedagógicas) promovidas pela Instituição, nos cursos técnicos, convergem para integração curricular? Assumimos como pressuposto que: essas ações têm se mostrado fragmentadas em relação às estratégias de integração previstas nos Projetos Pedagógicos desses cursos. Apresentamos como objetivo: compreender a relação entre as práticas pedagógicas e institucionais promovidas pelo Instituto e as estratégias de integração contidas nos PPCs.

O texto está estruturado em três partes: a primeira, evidenciamos o conceito de competência como pedagogia orientadora dos currículos da educação profissional de nível técnico. Na segunda, mostramos a discussão sobre a integração curricular. Na terceira, trazemos a busca do IFPB de articulação entre as estratégias contidas nos Projetos Pedagógicos dos Cursos Técnicos Integrados e as práticas pedagógicas e institucionais.

\section{COMPETÊNCIA NO CURRÍCULO}

Nas duas últimas décadas, tem havido um processo de reestruturação, por meio de reformas, apontadas como necessárias, em função das mudanças processadas na organização do trabalho pela denominada revolução tecnológica, gerando o discurso da pauta da acumulação flexível. Para Antunes (2000, p. 210), houve na década de 1980 grande salto tecnológico, despertando para um debate sobre automação e as mutações organizacionais, além de novos processos de trabalho que emergem, flexibilizando a produção, novos padrões de produtividade, ou novas formas de adequação ao mercado. Em síntese, a nova organização do trabalho e de suas formas de gestão passaram a exigir um trabalhador com um novo perfil, a partir do desenvolvimento de competências cognitivas. As reformas educacionais, processadas no âmbito da produção, na força produtiva e nessa organização laboral, influenciam as concepções de ensino, formação e qualificação. No entendimento de Ramos (2001, p. 1),

[...] as reformas realizadas em alguns países europeus-França, Inglaterra e Espanha - e latino-americanos - México, Chile, Argentina e Brasil - têm-se justificado pela necessidade de adequar a educação às demandas do mundo contemporâneo, tomando-se como base pressupostos e teorias psicológicas. Tem-se, assim, verificado uma forte adesão a uma concepção construtivista de aprendizagem, para a qual são de grande importância as ideias de memorização compreensiva, funcionalidade do conhecimento e aprendizagem significativa.

No caso brasileiro, as mudanças processadas no sistema educacional foram influenciadas pelo encontro de Jomtien (Tailândia em 1990), onde foi elaborada a Declaração Mundial sobre 
Educação para Todos. Reformar a educação era uma prioridade mundial e as competências seriam o único caminho para oferecer de fato, uma educação para todos.

Com isso, na década de 1990, a ideologia da competência é adotada como visão central da prática educativa da educação profissional de nível técnico, no Brasil, cujo foco passa a ser o desenvolvimento de competência. A sua relevância no contexto da formação escolar é resultante do trabalho de autores como Philippe Perrenoud, a sua mais conhecida referência. $O$ desafio é a ruptura à tradição de uma prática centrada no ensino, promovendo a dicotomia teoria/prática. Conforme Frigotto $(2005$, p.7),

o ideário pedagógico das diretrizes curriculares centra-se numa concepção
produtivista e empresarial das competências e da competitividade, cujo papel é o
de desenvolver habilidades de conhecimentos, valores, atitudes e de gestão de
qualidade, definidas no mercado de trabalho e cujo objetivo é o de formar em
cada indivíduo um banco ou reserva de competências que lhe assegure
empregabilidade.

O arcabouço legal da reforma da educação profissional, as práticas pedagógicas dos currículos devem estar voltadas para o desenvolvimento de competências, caminhando no sentido de atender aos princípios da flexibilidade, da interdisciplinaridade e da contextualização.

A contextualização, por sua vez, promete mecanismos propícios à construção de significados pois agrega aprendizagens que têm sentido para o estudante como a sua realidade e a do mundo do trabalho. A interdisciplinaridade vista como mecanismo de superação da fragmentação disciplinar, por meio da qual as disciplinas isoladas são modificadas, passando a caracterizar uma relação de interdependência entre todas elas. Estes princípios manifestam-se como possibilidade para romper com a compartimentalização dos conhecimentos e de superar a divisão trabalho manual e trabalho prático. E como tem se efetuado essa integração no IFPB?

\section{INTEGRAÇÃO CURRICULAR}

A integração curricular foi resultante da mobilização de setores educacionais, sobretudo de sindicatos e pesquisadores da área de trabalho e educação, nos anos de 2003 e 2004, a favor da ruptura dessa política neoliberal do governo de Fernando Henrique. Gaudêncio Frigotto, Marise Ramos e Maria Ciavatta (2005, p.26) lançaram uma crítica às propostas ao governo seguinte, entendendo que: [...] no âmbito da elaboração das políticas para o ensino médio e para a educação profissional, a revogação do Decreto 2.208/97 tornou-se emblemática da disputa e a expressão pontual de uma luta teórica em termos de pertinência político-pedagógica do ensino médio integrado à educação profissional.

Para esses autores, tal fato passou a requerer um posicionamento político ou um afastamento do processo para se promover uma crítica com vistas a outro projeto. Houve o entendimento de que era possível trabalhar dentro das contradições do governo, objetivando fomentar um movimento a procura de modificações estruturais. Retoma-se a possibilidade de articulação do ensino médio à educação profissional, sendo promulgado o Decreto Lei no 5.154/004, em substituição ao Decreto no 2.208/97. Apesar de ter havido a garantia da articulação e integração desses níveis de ensino, contudo não houve avanço significativo em termos do ideário pedagógico. Acrescentou-se à visão anterior a forma - integrada, projeto pedagógico único em que a formação geral é articulada à formação profissional. Mesmo assim, mantiveram-se as formas concomitante e a subsequente. 
De acordo com aqueles autores citados, preferiu-se então retomar a discussão da educação básica integrada ao ensino médio, uma vez que a politecnia de "[...] forma universal e unitária", não encontraria base material concreta de sustentação. Para Saviani (2003, p.140), a politecnia diz respeito ao "[...] domínio dos fundamentos científicos das diferentes técnicas que caracterizam o processo de trabalho produtivo moderno". Para aqueles três autores citados (2005, p.15), o ensino médio integrado se constitui de uma proposta de travessia para o atendimento aos milhares de jovens com direito ao ensino médio pleno. Por sua vez, carecem de se inserir no sistema produtivo. O ensino médio integrado é condição social e histórica necessário para a construção de ensino médio unitário e politécnico.

Isso significa entender o trabalho como princípio educativo, como um direito cuja gênese advém da necessidade humana. A exploração, pelo trabalho, é apenas uma configuração de uma relação desigual de poder das relações sociais. É preciso considerar os princípios norteadores do ensino médio integrado à educação profissional, ou seja, as categorias trabalho, ciência, tecnologia e cultura como o centro de uma nova forma de organização curricular. Por sua vez, Moura (2012, p.9) corrobora com esse sentido do trabalho ao afirmar que:

[...] É precisamente a partir do tensionamento entre o trabalho em sua dimensão ontológica e a constituição histórica do trabalho alienado que Gramsci localiza o trabalho como princípio educativo. Ao pensar a organicidade entre trabalho e educação, Gramsci a localiza enquanto processo por meio do qual o homem adquire propriamente as condições de humanização, processo este circunstanciado pela historia e pelos modos de produção da existência.

A perspectiva dessa centralidade da vida, contudo, acompanha simultaneamente a produção da tecnologia. Esta, passando ao centro das práticas sociais, está presente no mundo complexo do processo da pesquisa e, em especial, do mundo educativo. Mas, com destaque de não poderem estar deslocados como entes separados e existindo por si mesmos. O trabalho como categoria central da produção de saber, produtor da ciência e tecnologia, os expressa como indissociáveis.

Para Lopes (2008), na atualidade, especialmente nas definições oficiais de currículo, mas não exclusivamente elas, a defesa de um Currículo Integrado como justificativa para atender o mundo do trabalho vem sendo denominado 'mudanças no mundo globalizado'. Nessas mudanças, as ciências e o mundo produtivo estão intrinsecamente articulados, na medida em que o conhecimento científico e a tecnologia, cada vez mais, são revelados como base da produção capitalista. Já para Bernstein (1996), a ideia de integração refere-se aos processos de compartimentalização de saberes. Para ele, o conceito de integração não se confunde com interdisciplinaridade porque a integração se produz em vários conteúdos que estão subordinados a uma ideia centralizadora, em um todo mais amplo.

Ainda com a discussão sobre trabalho, as análises de Ramos e Ciavatta (2012) sobre o Currículo Integrado têm como questão central a categoria trabalho e sua historicidade. Em síntese, esses estudos examinam a dinâmica histórica das relações e processos de trabalho nessa sociedade em geral e, mais especificamente, no Brasil.

A ciência e a tecnologia nos cursos técnicos integrados ao ensino médio e o fenômeno mais amplo que é a cultura, eixos estruturadores do currículo integrado, podem ser entendidas enquanto condição humana de produzir os entes da natureza, produção universal. Esses eixos vão formar uma compreensão de currículo revelando-se como ambiente de contradições e relações de 
poder. Para Giroux (1997), as escolas são espaços de contradição, pois ao mesmo tempo que reproduzem a sociedade mais ampla, contêm espaço para resistir a sua lógica de dominação. Para Chauí (1986), essa dominação pauta-se em fatos e situações da cultura popular nos quais podem ser constatadas manifestações de conformismo e de resistência.

O currículo é produto de tensões, de conflitos sociais, de concessões culturais, políticas e econômicas que guiam o contexto da sua produção e, como tal, não é meramente composto de técnicas, procedimentos e métodos, mas sim um artefato social, que se orienta por questões sociológicas, políticas e epistemológicas. Para Elias (1998), a construção das políticas curriculares pode ser vista como um processo "abastecido pelas tensões e conflitos estruturais reprimidos na escola". No IFPB, o currículo integrado se revela como uma possibilidade de efetivação apesar da resistência de profissionais. Mas, como se materializa essa integração no IFPB?

\section{PRÁTICAS INTEGRADORAS INSTITUCIONAIS - IFPB}

Trabalhar essa perspectiva do Currículo Integrado passa por uma ruptura com as concepções de educação e ensino desvinculadas da realidade. No IFPB, existe uma diversidade de projetos de formação que promete a articulação ou integração entre teoria e prática. Entre eles, o Ensino Técnico Integrado que emerge em contraposição à pedagogia das competências. $O$ que as diferenciam, então? Segundo Araújo, (2013, p.14), é a integração entre teoria e prática ou a práxis, o compromisso com a mudança social.

Nessa perspectiva, são necessárias práticas integradoras que favoreçam esse princípio, requerendo uma nova postura diante da ação educativa. A perspectiva da integração curricular, a interdisciplinaridade, a contextualização, o projeto integrador emergem como formas de unidade didática integradora.

Um olhar sobre o Projeto Pedagógico do Curso Técnico de Mecânica Integrado ao Ensino Médio (2006, p. 38), a respeito das estratégias de integração curricular, propostas no Decreto no 5.154/2004, mostram que se dará:

\footnotetext{
[...] com base nos pensadores da educação "integral" a proposta curricular para o ensino integrado contemplará uma metodologia formadora, fundada na "pedagogia do trabalho", identificada como a possibilidade de conduzir o alunado a compreender que, mais do que dominar conteúdos, deverá aprender a se relacionar com o conhecimento de forma ativa, construtiva e criadora, balizados pelos eixos curriculares trabalho, ciência e cultura, bem como por um percurso metodológico que abarque a problematização, a teorização, a formulação de hipóteses e a intervenção na realidade.
}

Além disso, no item ainda sobre a metodologia há o destaque de que [...] dever-se-á: desenvolver projetos interdisciplinares e integradores em nível de conhecimentos e de oportunidades com situações reais de vida e do trabalho (2006, p.38). Todavia, não identificamos como será esse percurso metodológico e nem que estratégias serão utilizadas pela Instituição para dá conta da transposição didática dessa pedagogia para as práticas pedagógicas integradoras.

Um outro documento orientador na integração curricular do IFPB é o Plano Pedagógico de Curso - PPC (2013), referência para os diversos campi do Instituto na elaboração dos projetos dos cursos técnicos integrados. Esse documento é atualização das novas diretrizes de educação profissional (2013, p.28) e traz no item das Práticas Pedagógicas previstas a necessidade: 
para viabilizar aos educandos o desenvolvimento de competências relacionadas às bases técnicas, científicas e instrumentais, serão adotadas, como prática metodológica, formas ativas de ensino-aprendizagem, baseadas em interação pessoal e do grupo, sendo função do docente criar condições para a integração dos estudantes a fim de que se aperfeiçoe o processo de socialização na construção do saber.

Nesse mesmo item, temos listada uma diversidade de técnicas de ensino, dentre elas: a) utilização de aulas práticas; b) aulas expositivas, dialogadas; $c$ ) pesquisas sobre os aspectos teóricos e práticos; d) discussão de temas; e) aulas expositivas; f) estudos de caso, g) debates provenientes de pesquisa prévia; h) seminários; i) abordagem sobre as novas tecnologias da informação e da comunicação; j) dinâmicas de grupo; k) palestras com profissionais da área e I) visitas técnicas. Percebemos algumas estratégias individualizadas não favorecendo a integração curricular.

Mesmo nessa perspectiva metodológica alguns princípios, como contextualização e interdisciplinaridade podem nortear essas estratégias de ensino e a organização de projetos integradores mais amplos. Sendo assim, qualquer mudança, passa, necessariamente, pela reconfiguração da visão de conhecimento que sustenta à concepção pedagógica. Além disso, a sociedade se reestrutura, se resignifica, daí pensar uma escola diferente. Corroborando com esse pensamento, Araújo (op.cit. p.25) evidencia que:

na operacionalização do ensino integrado, práticas pedagógicas que priorizem o trabalho coletivo, ao invés do trabalho individual,, devem ser, portanto, valorizadas, sem que isso signifique o abandono de estratégias de ensino e de aprendizagem individualizadas. Neste caso, entretanto, estas devem ser compreendidas como momentos intermediários para o trabalho coletivo de ensinar e aprender.

Com relação às práticas pedagógicas desenvolvidas pelo Instituto - os encontros pedagógicos, as oficinas e as reuniões pedagógicas - reforça-se a cultura institucional de realização dos mesmos, antes do início do ano letivo nos seus vários campi. Promovem esses encontros para o planejamento e a avaliação das atividades pedagógicas. A integração curricular tem sido uma das temáticas recorrente nesses momentos. Observemos que no Campus João Pessoa, a partir de 2004, já tivemos vários momentos de discussão e elaboração de propostas integradoras. Vejamos a síntese dos grupos de trabalho da oficina pedagógica Currículo Integrado (julho/2009). Naquela oportunidade, foram definidos para os cursos técnicos integrados de Controle Ambiental, Edificações, Eletrotécnica, Mecânica e Música temas, sub-temas a serem trabalhados por série. Alguns cursos conseguiram visualizar, inclusive, textos e atividades a serem materializados como referências.

Além da integração curricular, os PPCs foram uma das temáticas no Planejamento Pedagógico (março/2014). Como proposta de trabalho, os coordenadores de cursos, a partir da matriz curricular dos cursos técnicos integrados, precisariam pontuar a necessidade de integração com os docentes da formação geral. Quanto à continuação do processo de unificação curricular do Ensino Técnico Integrado ao Médio (ETIM), conforme as Diretrizes das Diretorias da DAPE e da Educação Profissional, visualizou-se a necessidade de: a) interação de docentes das áreas de conhecimento com a formação profissional na formulação de ementas e planos de ensino; b) discussão e formulação de Projetos Integradores da matriz curricular dos cursos; c) integração docente na formulação curricular; d) elaboração de projetos integradores e, e) retomar proposta de integração curricular (Prof. Casemiro-IFSC). Em especial, também neste Campus, destacamos a 
necessidade de continuidade dessas orientações definidas pelos próprios participantes do encontro.

\section{Grupos de Trabalho - Campus João Pessoa}

\begin{tabular}{|c|c|}
\hline Grupo I- Edificações & Grupo II- Eletrotécnica \\
\hline $\begin{array}{l}\text { Tema: Sustentabiliadade } \\
\text { Sub-temas: } \\
\text { Primeira série Impactos da construção civil no } \\
\text { meio ambiente. } \\
\text { Segunda série: Elaboração de projetos } \\
\text { arquitetônicos e topográficos. } \\
\text { Terceira série: Aplicação de materiais e } \\
\text { procedimentos executivos na construção civil. } \\
\text { Quarta-série: Execução, elaboração de projetos e } \\
\text { planejamentos de obras civis. } \\
\text {------------------ } \\
\text { Grupo III- Controle Ambiental/Música } \\
\text { Tema: Sustentabilidade } \\
\text { Sub-temas: } \\
\text { Primeira série: Energias alternativas, água (chuva). } \\
\text { Segunda série: Aquecimento global, mudanças } \\
\text { climáticas, resíduos sólidos. } \\
\text { Terceira série: Preservação do meio ambiente, } \\
\text { reciclagem. }\end{array}$ & $\begin{array}{l}\text { Tema: Eletricidade no nosso cotidiano } \\
\text { Sub-temas: Iluminação pública no período colonial. } \\
\text { Primeira série: Incidência de raios em diferentes } \\
\text { regiões do Brasil e do mundo. } \\
\text { Atividades: Visita ao Museu } \\
\text { São Francisco; pesquisas bibliográficas e exibição do } \\
\text { filme Aleijadinho. } \\
\text { Disciplinas envolvidas: } \\
\text { Segunda série: Instalações elétricas prediais (impactos } \\
\text { econômicos e sociais). } \\
\text { Origem da lâmpada incandescente e evolução das } \\
\text { lâmpadas. } \\
\text { Impactos ambientais causados pelo uso de Lâmpadas. } \\
\text { Terceira série: Instalação elétrica industrial, } \\
\text { Química orgânica, equilíbrio químico e cinética química. } \\
\text {--------------------------------------------------- } \\
\text { Grupo IV- Mecânica } \\
\text { Tema: Meio Ambiente. } \\
\text { Disciplinas envolvidas: Motores a } \\
\text { Combustão, Máquinas Elétricas, } \\
\text { Hidráulica, Refrigeração, Fundição, } \\
\text { Laboratório de Materiais de Construção, } \\
\text { Mecânica e as disciplinas da área de } \\
\text { Ciências Humanas podem dar sua } \\
\text { contribuição, através de textos. } \\
\text { Sub-temas: } \\
\text { 1. Uso adequado de máquinas } \\
\text { Atividades: tipos de manutenção e recomendações dos } \\
\text { fabricantes. } \\
\text { Textos: manuais e catálogos. } \\
\text { 2. Inovações tecnológicas para a preservação do meio } \\
\text { ambiente. } \\
\text { Atividades: trabalhos de pesquisa na busca de novas } \\
\text { tecnologias e visitas técnicas. } \\
\text { Textos: Internet, revistas, artigos, relatórios de visitas. } \\
\text { Proposta: Assinatura de revistas técnicas pela biblioteca. }\end{array}$ \\
\hline
\end{tabular}

No Campus Cajazeiras, em 2009, ocorreu a mesma oficina sobre Currículo Integrado e seus princípios. Efetuou-se o trabalho em grupos para definição de temas para os cursos de Edificações, Eletromecânica e Informática. Definiram os temas da 1a série. Restou ao grupo, em outro momento, a continuação do trabalho para as demais séries. Mas, não houve, posteriormente, perspectiva de continuidade dessa ação. 
Grupos de Trabalho - Campus Cajazeiras

\begin{tabular}{|l|l|}
\hline \multicolumn{1}{|c|}{ Grupo I- Edificações } & \multicolumn{1}{c|}{ Grupo II- Eletromecânica } \\
\hline Temas: & Temas: \\
Primeira série: preservação da escola & Energia \\
Disciplinas: Biologia, Língua Portuguesa, Materiais & $\underline{\text { Grupo III- Informática }}$ \\
de construção, Química, Artes, Geografia, & $\underline{\text { Temas: }}$ \\
Matemática, Informática e Desenho. & Mercado, Trabalho coletivo, Ética. \\
& Disciplinas: Informática Básica, \\
& Português Instrumental. \\
\hline
\end{tabular}

Naquele momento, os docentes e a equipe pedagógica destacaram as dificuldades para a implementação da integração curricular, dentre elas: a falta de conhecimento dos projetos dos cursos técnicos; falta de experiência coletiva; dificuldade de convergência de conteúdos para um mesmo curso e como integrar docentes de distintas disciplinas técnicas, sem encontros por áreas e cursos.

Já no Campus Monteiro, durante Encontro Pedagógico, ocorrido em março de 2012, a discussão não ficou só em torno do IFPB, conforme síntese dos grupos de trabalho, ampliando para a uma visão de organização da escola que está fora da realidade de adultos e adolescentes das classes populares. Para o grupo de docentes é preciso encontrar mecanismos que ajudem a melhorar as condições pedagógicas de acesso, permanência e aprendizagem. O debate sobre integração pautou a discussão geral do papel do IFPB na região do Cariri paraibano, sinalizando que a questão está para além dos conteúdos das disciplinas. Mas, carece de continuidade dessa ação de práticas pedagógicas integradoras.

No Campus Picuí (abril/2013), ocorreu também o encontro pedagógico com os seguintes temas: princípios do Currículo Integrado (cultura, trabalho, ciência e tecnologia); o papel do docente e do estudante; os conteúdos (que tenham significado socialmente), metodologia e avaliação nos cursos técnicos integrados. Possibilidades de integração curricular. Esse encontro contou com a participação efetiva de docentes e pedagogia. Na oportunidade, o trabalho foi orientado para que se construísse uma proposta de integração curricular, com metodologia e avaliação. Assim também neste Campus, ocorreram novos encontros, outras ações, mas sem a garantia da continuidade do que já estava sendo elaborado. Que considerações são possíveis de serem destacadas nesses exercícios de integração?

\section{CONCLUSÃO}

A ideia integradora envolve a relação dialógica entre docentes e estudantes, uma vez que a integração possui estreita relação com as experiências vivenciadas pelos por docentes que podem ser utilizadas no processo de transmissão dos conhecimentos ou práticas pedagógicas específicas.

Quando damos início a qualquer processo de elaboração ou revisão dos Projetos Pedagógicos de Cursos ainda que temos avançado em começar essa discussão pelo perfil da formação integrada, predomina uma ênfase na visão técnica de currículo como uniformização de matrizes curriculares, impedindo o avanço da integração curricular .

Comparando esses material produzido, bem como as práticas pedagógicas e institucionais desencadeadas pelos campi do Instituto, percebemos que o problema é que, apesar de várias propostas não se tem conseguido avançar em relação essa integração curricular. 
A construção da integração curricular demanda outra postura pedagógica - a forma de agir dos docentes, dos estudantes, da equipe pedagógica e de gestores, de uma nova cultura organizacional.

Um olhar atento à atual face e à dinâmica cotidiana do IFPB tende a exibir muito mais as cicatrizes de quem precisa romper com práticas consagradas para se tornar avançado e implementar mudanças tão necessárias aos dias atuais.

A ideia que se tem é que estamos sempre começando. Com certa margem de acerto, a integração do currículo prescinde de sistematização e continuidade em relação às propostas nesses encontros pedagógicos ou oficina. Enfim, estamos sempre insistindo em propostas sem a sua devida efetivação, reafirmando-se como um conjunto de práticas pedagógicas e institucionais fragmentadas.

\section{REFERÊNCIAS}

1. ANTUNES, Ricardo. Os sentidos do trabalho: ensaio sobre a afirmação e a negação do trabalho. 2. ed. São Paulo: Boitempo editorial, 2000.

2. ARAÚJO, Ronaldo Marcos de Lima. Práticas pedagógicas e ensino integrado. Belém, 2013.

3. BERNSTEIN, B. A. A estruturação do discurso pedagógico: classe, código e controle. Petrópolis: Vozes, 1996.

4. BRASIL. Ministério da Educação. Lei de Diretrizes e Bases da Educação Nacional - LDB no 9.394/96, de 20 de dezembro de 1996.

5. Lei 11.741, de 16 de julho de 2008. Altera dispositivos da LDB no 9.394/96.

6. Decreto Federal no 2.208/97, de 17 de abril de 1997.

7. Decreto Federal no 5.154/04, de 23 de julho de 2004.

8. Ministério da Educação. Secretaria de Educação Média e Tecnológica. Educação profissional: referenciais curriculares nacionais da educação profissional de nível técnico. Brasília, 2000. 19 v.

9. Parecer CNE/CEB no 17/1999, aprovado em 05 de outubro de 1999. Diretrizes Curriculares Nacionais para a Educação Profissional Técnica de Nível Médio.

10. CHAUI, Marilena. Conformismo e resistência, aspectos da cultura popular no Brasil. São Paulo: Editora Brasiliense, 1986.

11. CIAVATTA, Maria. A formação integrada: a escola e o trabalho como lugares de memória e de identidade In Ensino Médio Integrado: concepções e contradições. 3a edição. São Paulo, Cortez. 2005.

12. CIAVATTA, Maria e RAMOS, Marise."A era das diretrizes": a disputa pelo projeto de educação dos mais pobres. Revista Brasileira de Educação, v.17. n. 49. 2012.

13. ELIAS, Nobert. Envolvimento e alienação. Tradução do inglês por Álvaro de Sá. Rio de Janeiro: Bertrand Brasil, 1998.

14. FRIGOTTO, Gaudêncio. Concepções e mudanças no mundo do trabalho e o ensino médio In: RAMOS, Marise CIAVATTA, Maria (Orgs). Ensino Médio Integrado: concepções e contradições.3a edição. São Paulo, Cortez. 2005. 
15. RAMOS, Marise CIAVATTA, Maria(orgs). Ensino Médio Integrado: concepções e contradições. 3. ed. São Paulo: Cortez. 2005.

16. GIROUX, H. Os docentes como intelectuais: rumo a uma pedagogia crítica da aprendizagem. Porto Alegre: Artes Médicas.1997.

17. IFPB. Projeto Pedagógico do Curso Técnico de Mecânica Integrado ao Ensino Médio. Instituto Federal de Educação, Ciência e Tecnologia da Paraíba, 2006.

18. Projeto Pedagógico do Curso Técnico Integrado ao Ensino Médio (modelo). Instituto Federal de Educação, Ciência e Tecnologia da Paraíba, 2013.

19. Planejamento Pedagógico. Campus João Pessoa. João Pessoa, 2014.

20. Planejamento Pedagógico. Campus Cajazerias. Cajazeiras, 2009.

21. Planejamento Pedagógico. Campus Monteiro. Monteiro, 2012.

22. Planejamento Pedagógico. Campus Picuí. Picuí, 2013.

23. LOPES, Alice Casimiro. Políticas de integração curricular. Rio de Janeiro EdUERJ.2008.

24. MOURA, Dante Henrique. A organização curricular do ensino médio integrado a partir do eixo estruturante: trabalho, ciência, tecnologia e cultura. Revista Labor. no 7, v.1, 2012.

25. RAMOS, Marise Nogueira. O "novo" ensino médio à luz dos antigos princípios: trabalho, ciência e cultura. Boletim Técnico do SENAC, vol.29, n.2. Rio de janeiro, pp.19-27, maio/agosto, 2003.

26. A pedagogia das competências: autonomia ou adaptação? São Paulo: Cortez, 2012.

27. Possibilidades e desafios da organização do Currículo Integrado. In: RAMOS, Marise (Org.); FRIGOTTO, Gaudêncio (Org.); CIAVATTA, Maria (Org). Ensino Médio Integrado: concepções e contradições. 3. ed. São Paulo: Cortez. 2005, pp.106-127.

28. SAVIANI, Dermeval. O choque teórico da politecnia. Educação, Trabalho e Saúde. Rio de Janeiro: EPSJV/FIOCRUZ, 2003, v.1, p.131-152. 